\title{
Design and Evaluation of Metoprolol Tartrate Containing Buccal Tablets
}

\author{
D. Nagendrakumarr ${ }^{1}$, S. B. Shirsand ${ }^{2}$, M.S. Para ${ }^{1}$ and C.K. Makadia ${ }^{1}$ \\ ${ }^{1}$ Department of Pharmaceutics, S. V. E. Trust's College of Pharmacy, Humnabad -585 330, \\ Dist.-Bidar, Karnataka \\ ${ }^{2}$ Department of Pharmaceutical Technology, H. K. E. Society's College of Pharmacy, \\ Gulbarga-585 105, Karnataka
}

\begin{abstract}
Metoprolol tartrate is a selective $\beta-1$ adrenergic antagonist used in the treatment of the cardiovascular system, especially hypertension. It is readily and completely absorbed from the gastrointestinal tract but is subjected to considerable first- pass metabolism having half-life of 3 to $4 \mathrm{hr}$. It has $12 \%$ oral bioavailability. These physicochemical properties of metoprolol tartrate (undergoing considerable first- pass metabolism, low molecular weight) make it suitable candidate for administration by buccal route. Bilayered buccal tablets of metoprolol tartrate were prepared by direct compression method using combinations of polymers (carbopol $934 \mathrm{p}$ along with sodium carboxy methyl cellulose, sodium alginate and hydroxy propyl methyl cellulose $\mathrm{K} 4 \mathrm{M}$ ), using mannitol as a channeling agent and ethyl cellulose as a backing layer. The tablets were evaluated for physical and biological parameters. Among the 15 formulations, the formulation $\mathrm{FA}_{1}$ containing sodium alginate $(34.00 \% \mathrm{w} / \mathrm{w}$ of matrix layer), Carbopol $934 \mathrm{p}(6.0 \% \mathrm{w} / \mathrm{w}$ of matrix layer) and mannitol (channeling agent, $8.0 \% \mathrm{w} / \mathrm{w}$ of matrix layer) was found to be promising, which showed $\mathrm{t}_{25 \%}, \mathrm{t}_{50 \%}, \mathrm{t}_{70 \%}$ values of $0.42,2.45,4.48 \mathrm{hr}$ respectively and in vitro drug release of $86.04 \%$ in $8 \mathrm{hr}$ along with satisfactory bioadhesive strength $(5.00 \pm 0.10 \mathrm{~g})$. Stability studies on the promising formulations indicated that there are no significant changes in drug content and in vitro dissolution characteristics $(\mathrm{p}<0.05)$. Infra-redspectroscopic studies indicated that there are no drug-excipient interactions. The prepared buccal tablets of metoprolol tartrate could stay in the buccal cavity for a longer period of time, which indicate a potential use of mucoadhesive tablets of metoprolol tartrate for treating blood pressure.
\end{abstract}

Key words: mucoadhesive buccal tablets; metoprolol tartrate; carbopol 934p; sodium carboxy methyl cellulose; sodium alginate; hydroxy propyl methyl cellulose K4M; bioadhesive strength; in vitro dissolution.

\section{INTRODUCTION}

Among the various routes of drug delivery, the oral route is perhaps the most preferred by patients and clinicians alike. However, peroral administration of drugs has disadvantages, such as hepatic first-pass metabolism and enzymatic degradation within the gastrointestinal tract (GIT). So, there has been a growing interest in the use of delivery of therapeutic agent through various transmucosal routes to provide a therapeutic amount of drug to the proper site in body to promptly achieve and then maintain the desired concentration. Consequently, other absorptive

Correspondence to: S.B. Shirsand

E mail: shirsand@rediffmail.com

Dhaka Univ. J. Pharm. Sci. 10(2): 101-108, 2011 (December) mucosa are considered as potential sites for drug administration. Transmucosal routes of drug delivery (i.e. the mucosal linings of the oral, nasal, rectal, vaginal and ocular cavities) offer distinct advantages over peroral administration for systemic effect. ${ }^{1}$

The unique environment of the oral cavity offers its potential as a site for drug delivery. These advantages include: 1) The drug is not subjected to the destructive acidic environment of the stomach. 2) Therapeutic serum concentration of the drug can be achieved more rapidly. 3) The drug enters the general circulation without first passing through the liver.

The mouth lined with a mucous membrane and among the least known of its functions is its capability of serving as a site for the absorption of drugs. ${ }^{2}$ In general, drugs penetrate the mucous 
membrane by simple diffusion and are carried in the blood, which richly supplies the salivary glands and their ducts into the systemic circulation via the jugular vein. Active transport, pinocytosis and passage through aqueous pores usually play only insignificant roles in moving drugs across the oral mucosa. ${ }^{3}$ Two sites within the buccal cavity have been used for drug administration. Using the sublingual route, in this the medication is placed under the tongue, usually in the form of rapidly dissolving tablet. The second anatomic site for drug administration is between the cheek and gingival, although this second application site is itself known as buccal absorption.

The thin mucin film, which exists on the surface of the oral mucosa may provide an opportunity to retain a drug delivery system in contact with the mucosa for prolonged period, if it is designed to be mucoadhesive. Such system ensures close contact with absorbing membrane, thus optimizing the drug concentration gradient across the biological membrane and reducing the differential pathway.

In addition, it should release the drug in a unidirectional way towards the mucosa, in a controlled and predictable manner, to elicit the required therapeutic response. This unidirectional release can be achieved using bilayer device. Therefore, the oral mucosa may be potential site for controlled or sustained drug delivery. The permeability of the oral mucosa is low; hence the oral mucosa could be utilized to potent drugs which are required in small doses. ${ }^{4}$

Bioadhesion may be defined as the state in which two materials, at least one of which is of a biological nature, are held together for extended periods of time by interfacial forces. For drug delivery purposes, the term bioadhesion implies attachment of a drug carrier system to a specific biological location. The biological surface can be epithelial tissues or the mucous coat on the surface of a tissue. If adhesive attachment is to a mucous coat, the phenomenon is referred as mucoadhesion. Generally, It has been proposed that mucoadhesion occurs in three stages. The first stage involves the formation of an intimate contact between the mucoadhesive and mucous. Secondly, the mucoadhesive macromolecules swell and penetrate the mucuos macromolecules, becoming physically entangled. Thirdly, these molecules interact with each other via secondary, non-covalent bonds such as hydrogen bonds.

Metoprolol tartrate is a selective $\beta-1$ adrenergic antagonist used in the treatment of the cardiovascular system. This drug,with $12 \%$ oral bioavailability and having half-life of 3 to $4 \mathrm{hr}$, is readily and completely absorbed from the gastrointestinal tract but is subjected to considerable first-pass metabolism. These physicochemical properties of metoprolol tartrate make it suitable candidate for administration by buccal route. Since the buccal route bypasses firstpass effect, the dose of metoprolol tartrate could be reduced by $50 \%$. Therefore, the present study is aimed to prepare and evaluate buccal tablets of metoprolol tartrate, in order to overcome bioavailability related problems, to reduce dose dependent side effects and frequency of administration. ${ }^{5}$

\section{MATERIALS AND METHODS}

Metoprolol tartarte (Astra Zeneca Ltd., Bengaluru), Ethyl cellulose (Arihant Trading co., Mumbai, India), Hydroxy propyl methyl cellulose K4M (Colorcon Asia Pvt. Ltd., Verna, India) Carbopol 934p (ShinEtsu Chemical Co. Ltd., Japan), Sodium carboxy methyl cellulose and sodium alginate (Loba Chemie, Mumbai) were gifted by the mentioned suppliers. All other materials were of analytical or pharmacopoeial grade and used as received.

\section{Method of preparation of buccoadhesive tablets}

Preparation. Direct compression method has been employed to prepare buccal tablets of metoprolol tartrate using carbopol 934p along with sodium carboxy methyl cellulose, sodium alginate and HPMC K4M as polymers.

Procedure. All the ingredients including drug, polymer and excipients were weighed accurately according to the batch formulae (table-1). The drug is thoroughly mixed with mannitol on a wax paper with 
the help of a stainless steel spatula. Then all the ingredients except lubricant were mixed in the order of ascending weights and blended for $10 \mathrm{~min}$ in an inflated polyethylene pouch. After uniform mixing of ingredients, lubricant was added and again mixed for $2 \mathrm{~min}$. The prepared blend $(200 \mathrm{mg})$ of each formulation was pre-compressed on 10-station rotary tablet punching machine (Clit, Ahmedabad) at low pressure (approximately 2 to $2.5 \mathrm{~kg} / \mathrm{cm}^{2}$ ) to form single layered flat faced tablet of $8 \mathrm{~mm}$ diameter. Then, $50 \mathrm{mg}$ of ethyl cellulose powder was added and final compression was done at a pressure of 4.5 $\mathrm{kg} / \mathrm{cm}^{2}$ to get the bilayer tablet. ${ }^{6,7}$

Evaluation of bilayered buccal tablets of metoprolol tartrate. The prepared batches of tablets were evaluated for weight variation, hardness, friability, drug content uniformity,swelling index, surface $\mathrm{pH}$, ex vivo mucoadhesive strength, invitro drug release, stability studies and drug-excipient interaction (IR spectroscopy).

Twenty tablets were selected at random and weighed individually. The individual weights were compared with the average weight for determination of weight variation. Hardness and friability of the tablets were determined by using Monsanto hardness tester and Roche friabilator respectively. For content uniformity test, ten tablets were weighed and powdered. The powder equivalent to $25 \mathrm{mg}$ of drug was extracted into methanol, filtered through $0.45 \mu \mathrm{m}$ membrane filter disc (Millipore Corporation) and was analyzed for metoprolol tartrate after appropriate dilution by measuring the absorbance at $274.0 \mathrm{~nm}$, against blank. The drug content was calculated using the standard calibration curve. The mean percent drug content was determined as an average of three determinations.

Swelling index. The swelling rate of the tablet was evaluated by using $\mathrm{pH} 6.8$ phosphate buffer. The initial weight of tablet was determined $\left(\mathrm{W}_{1}\right)$. The tablet was placed in $\mathrm{pH} 6.8$ phosphate buffer $(6 \mathrm{ml})$ in a petridish placed in an incubator at $37 \pm 1^{\circ} \mathrm{C}$ and the tablet is removed at different time intervals $(0.5$, $1,2,3,4,5,6,7,8 \mathrm{hr}$ ), blotted with filter paper and reweighted $\left(\mathrm{W}_{2}\right)$. The obtained $\%$ Swelling index $=$ $\left[\left(\mathrm{W}_{2}-\mathrm{W}_{1}\right) / \mathrm{W}_{1}\right] \times 100$ (Figure 1). ${ }^{8,9}$

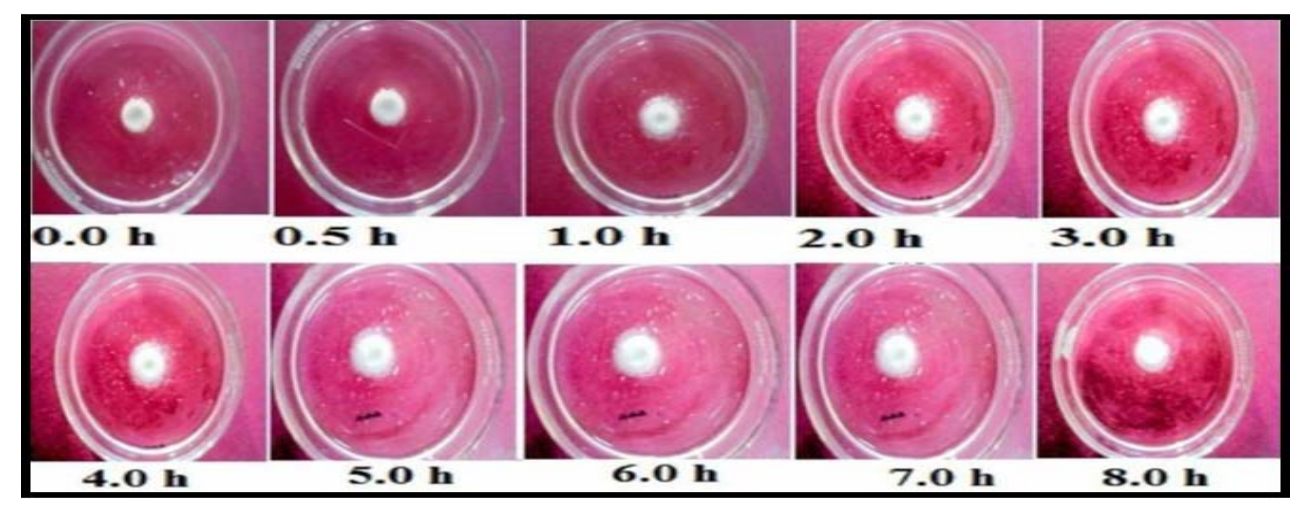

Figure 1. Swelling index study of the formulations.

Surface pH. The surface $\mathrm{pH}$ of the tablets was determined in order to investigate the possibility of any side effects on the oral cavity. As acidic or alkaline $\mathrm{pH}$ is found to cause irritation to the buccal mucosa, hence an attempt has been made to keep the surface $\mathrm{pH}$ close to the neutral $\mathrm{pH}$. A combined glass electrode is used for this purpose. Buccoadhesive tablets were left to swell for $2 \mathrm{hr}$ on the surface of 1 $\mathrm{ml}$ of distilled water $(\mathrm{pH} 6.8 \pm 0.05)$ at room temperature. The surface $\mathrm{pH}$ was measured by means of electrode by bringing it in contact with the tablet surface and allowing to equilibrate for $1 \mathrm{~min}^{10}$

Bioadhesive force. The apparatus used for testing bioadhesion was assembled in the laboratory. Bioadhesive strength of the buccal tablets was measured on the "Modified Physical Balance 
Method" employing the method described by Gupta et al using bovine cheek pouch as model mucosal membrane. The method used sheep buccal membrane as the model mucosal membrane.

A double beam physical balance was taken. The left pan was removed. To left arm of a balance, a thick thread of suitable length was hanged. To the bottom side of thread a glass stopper with uniform surface was tied. A clean glass mortar was placed below hanging glass stopper. In this, mortar was placed on a clean $500 \mathrm{ml}$ glass beaker, within which another glass beaker of $50 \mathrm{ml}$ capacity in inverted position was placed and weighed with $50 \mathrm{gm}$ to prevent floating. The pan control system involves placing thermometer in $500 \mathrm{ml}$ beaker and intermittently adding hot water in outer mortar filled with water. The balance so adjusted that, right hand side was exactly $5 \mathrm{gm}$ heavier than the left.

Method. The balance adjusted as described above was used for the study. The bovine cheek pouch excised and washed, was tied tightly with mucosal side upward using the thread over the base of inverted $50 \mathrm{ml}$ glass beaker. This beaker suitably weighted was lowered into $500 \mathrm{ml}$ beaker, which was then filled with isotonic phosphate buffer ( $\mathrm{pH}$ 6.8), kept at $37^{\circ} \mathrm{C}$ such that, the buffer reaches the surface of mucosal membrane \& keeps it moist. This was then kept below left hand side of balance. The buccal tablet was then stuck to glass stopper through its backing membrane using an adhesive (feviquick). The $5 \mathrm{gm}$ on right hand side is removed. This causes application of $5 \mathrm{gm}$ of pressure on buccal tablet overlying moist mucosa. The balance was kept in this position for $3 \mathrm{~min}$ and then slowly weights were increased on right pan, till tablet separates from mucosal membrane. The total weight on right pan minus $5 \mathrm{gm}$ gives the force required to separate tablet from mucosa. This gives bioadhesive strength in grams. The mean value of three trials was taken for each set of formulations. After each measurement, the tissue was gently and thoroughly washed with isotonic phosphate buffer and left for $5 \mathrm{~min}$ before reading a new tablet of same formulation to get reproducible multiple results for the formulation. ${ }^{11}$ (Figure 2)

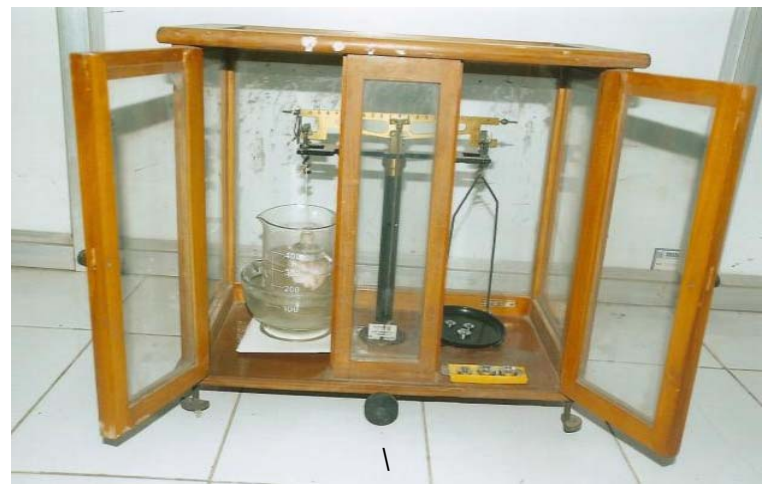

Figure 2. Mucoadhesive strength study of the formulations

Bio adhesive force $=\frac{\text { mucoadhesivestrenght }}{100}(9.81)$

In vitro drug release. Drug release was studied by using the USP XIII dissolution test apparatus (Electro Lab, TDT-08L) by using rotating basket at $37 \pm 0.5^{\circ} \mathrm{C}$ at $100 \mathrm{rpm}$. Tablet was added to $900 \mathrm{ml}$ of phosphate buffer of $6.8 \mathrm{pH}$. Samples were withdrawn at specified time intervals $(0.5,1,2,3,4,5,6,7$ and 8 hr) and replaced with fresh dissolution medium (phosphate buffer $\mathrm{pH}$ 6.8). The amount of drug released was determined spectrophotometrically at $274 \mathrm{~nm}$. The release rate study was carried out in triplicate for $8 \mathrm{hr}$.

Stability studies. Accelerated stability studies were performed at a temperature of $40 \pm 2^{\circ} \mathrm{C}$ and 75 $\pm 5 \% \mathrm{RH}$ over a period of three months (90 days) on the promising buccal tablets of metoprolol tartrate (formulation $\mathrm{FA}_{1}$ ). Sufficient number of tablets (25) were packed in amber colored rubber stoppered vials and kept in stability chamber maintained at $40 \pm 2{ }^{\circ} \mathrm{C}$ and $75 \pm 5 \%$ RH. At an interval of one month, the tablets were usually examined for any physical changes and also changes in drug content and in drug release profile.

Drug-excipient interaction studies. The IR spectra of metoprolol tartrate, carbopol 934 p, sodium CMC, sodium alginate, HPMC K4M, mannitol, sodium stearyl fumarate and formulations $\left(\mathrm{FA}_{4}, \mathrm{FC}_{4}\right.$, $\mathrm{FH}_{4}$ ) were obtained by $\mathrm{KBr}$ pellet method. (Shimadzu Corporation Japan FTIR-8400S Spectrometer). 


\section{RESULTS AND DISCUSSION}

The main goal of this work is to develop new buccoadhesive bilayered tablets of metoprolol tartrate consisting of drug free non- adhesive protective layer (backing layer). The double layered structure design was expected to provide drug delivery in an unidirectional fashion to the mucosa and to avoid loss of drug due to wash out by saliva, release the drug immediately to produce a prompt pharmacological action and remain in oral cavity, to provide a sustained release of drug over an extended period of time.

Bilayered buccal tablets were prepared by direct compression method using combinations of polymers (carbopol $934 \mathrm{p}$ along with sodium $\mathrm{CMC}$, sodium alginate and HPMC K4M), mannitol as a channeling agent and ethyl cellulose as a backing layer.

The bilayered buccal tablets were evaluated for physical parameters like appearance, hardness, thickness, weight variation, friability, swelling index and surface $\mathrm{pH}$; biological parameter- mucoadhesive strength; and other parameters such as drug content uniformity, in vitro drug release, stability studies, drug-excipient interaction (IR study).

The appearance of buccal tablets was smooth and uniform. The hardness of prepared buccal tablets of metoprolol tartrate was found to be in the range of 4.47 to $4.59 \mathrm{~kg} / \mathrm{cm}^{2}$.

The thickness and weight variation were found to be uniform as indicated by the low values of standard deviation. The thickness and weight of the prepared buccal tablets were found to be in the range of 5.03 to $6.03 \mathrm{~mm}$ and 250.7 to $255.2 \mathrm{mg}$ respectively. Friability values less than $1 \%$ indicate good mechanical strength to withstand the rigors of handling and transportations.

The average drug content of buccal tablets was found to be within the range of 95.65 to $100.06 \%$ and low values of standard deviation indicate uniform distribution of the drug within the prepared buccal tablets.

The surface $\mathrm{pH}$ was determined in order to investigate the possibility of any side effects in the oral cavity as acidic or alkaline $\mathrm{pH}$ is found to cause irritation to the buccal mucosa. Surface $\mathrm{pH}$ of all formulations was found to be in the range of 5.87 to 6.71. So it is assumed that these formulations will not cause any irritation in the oral cavity.

The swelling profile of different batches of the tablets indicate the uptake of water into the tablet matrix, producing an increase in weight. The swelling state of the polymer in the formulation was reported to be crucial for its bioadhesive behavior. Adhesion occurs shortly after the beginning of swelling but the bond formed between mucosal layer and polymer is not very strong. The adhesion will increase with the degree of hydration until a point where overhydration leads to an abrupt drop in adhesive strength due to disentanglement at the polymer/tissue interface. In formulations, maximum swelling was found $90.89 \pm 0.71$ with the formulation $\mathrm{FH}_{4}$ containing HPMC K4M (28.0\% w/w of matrix layer) with carbopol $934 \mathrm{p}(12.0 \% \mathrm{w} / \mathrm{w}$ of matrix layer). Results indicate that as the concentration of carbopol $934 \mathrm{p}$ increases, the swelling index increases.

The mucoadhesion of all the buccal tablets with varying ratio of polymers were tested and weight required to pull off the formulation from the mucous tissue is recorded as mucoadhesion strength in grams. The mucoadhesivity of buccal tablets was found to be maximum in case of formulation $\mathrm{FH}_{4}$ i.e. $7.33 \mathrm{~g}$. This may be due to fact that positive charges on the surface of Carbopol $934 p$ could give rise to strong electrostatic interaction with mucous or negatively charged mucus membrane.

In vitro release studies were carried out in USP XIII tablet dissolution test apparatus employing paddle stirrer at $100 \mathrm{rpm}$ and $900 \mathrm{ml}$ of $\mathrm{pH} 6.8$ phosphate buffer as dissolution medium. The in vitro dissolution profiles are depicted in figure 3 to 5 . From dissolution data, it is evident that designed formulations have displayed more than $61.71 \%$ drug release in $8 \mathrm{hr}$. In vitro drug release data of all the buccal tablet formulations of metoprolol tartrate was subjected to goodness of fit test by linear regression analysis according to zero-order, first order kinetics, Higuchi's and Peppas equations to ascertain mechanism of drug release. It is evident that all the 
formulations displayed zero- order release kinetics $\left(\mathrm{r}^{2}\right.$ values from 0.823 to 0.939 ). Higuchi and Peppas data reveals that the drug is released by non-Fickian diffusion mechanism ( $r^{2}$ values from 0.902 to 0.995$)$.

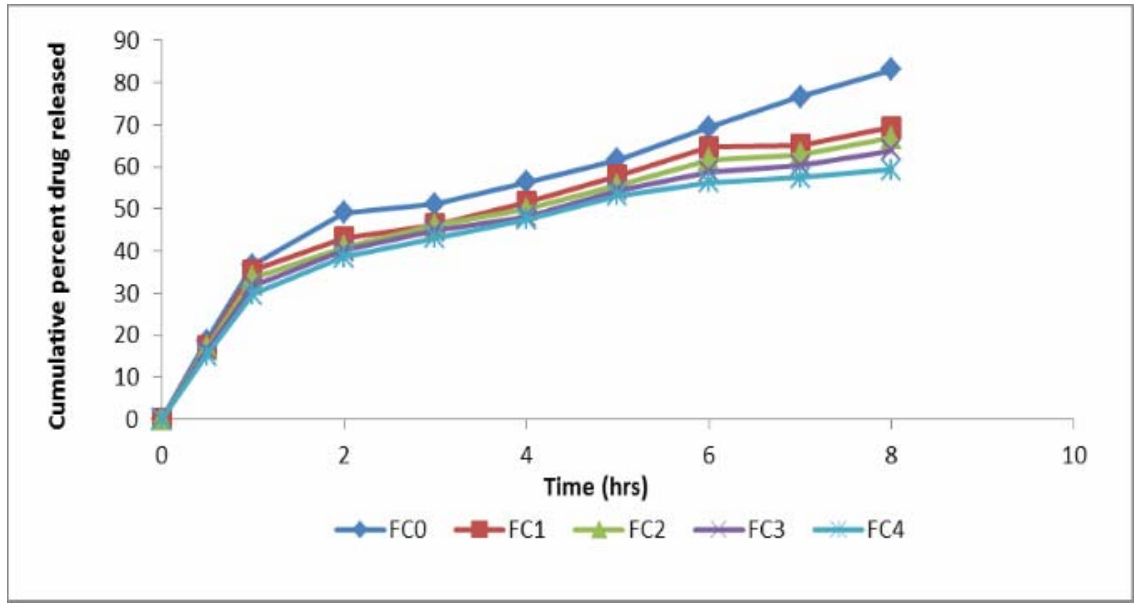

Figure 3. Cumulative percent drug released Vs time plots (zero order) of formulations $\mathrm{FC}_{0}, \mathrm{FC}_{1}, \mathrm{FC}_{2}, \mathrm{FC}_{3}$ and $\mathrm{FC}_{4}$.

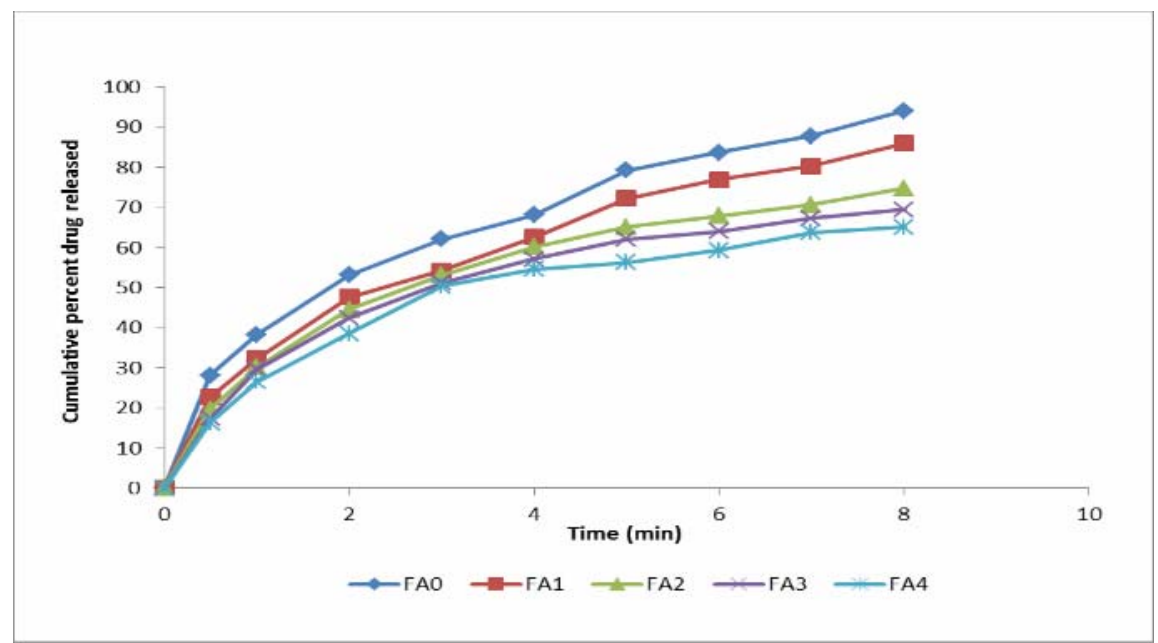

Figure 4. Cumulative percent drug released Vs time plots (zero order) of formulations $\mathrm{FA}_{0}, \mathrm{FA}_{1}, \mathrm{FA}_{2}, \mathrm{FA}_{3}$ and $\mathrm{FA}_{4}$.

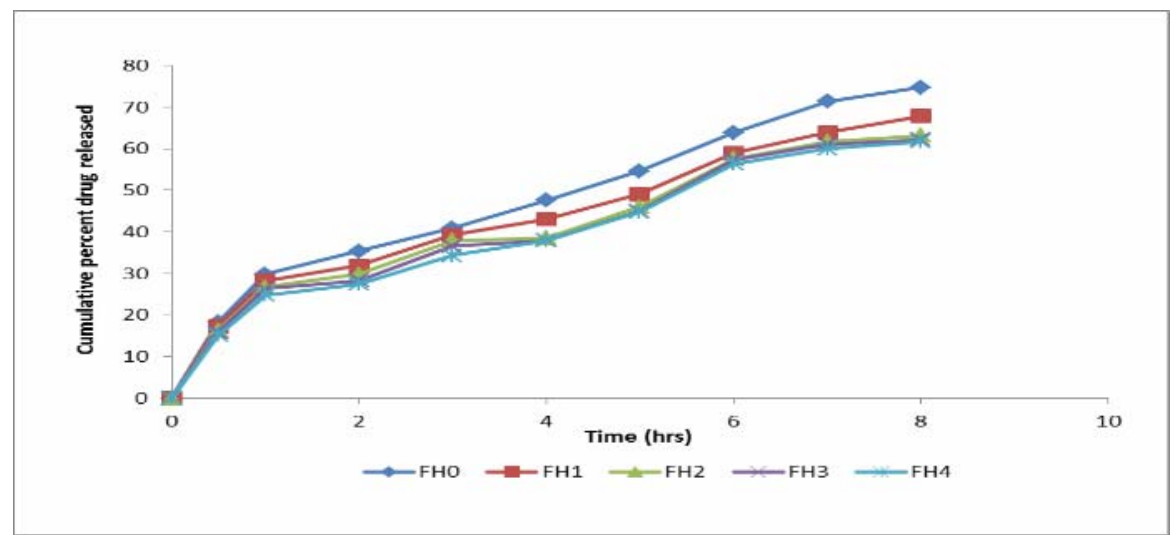

Figure 5. Cumulative percent drug released Vs time plots (zero order) of formulations $\mathrm{FH}_{0}, \mathrm{FH}_{1}, \mathrm{FH}_{2}, \mathrm{FH}_{3}$ and $\mathrm{FH}_{4}$. 


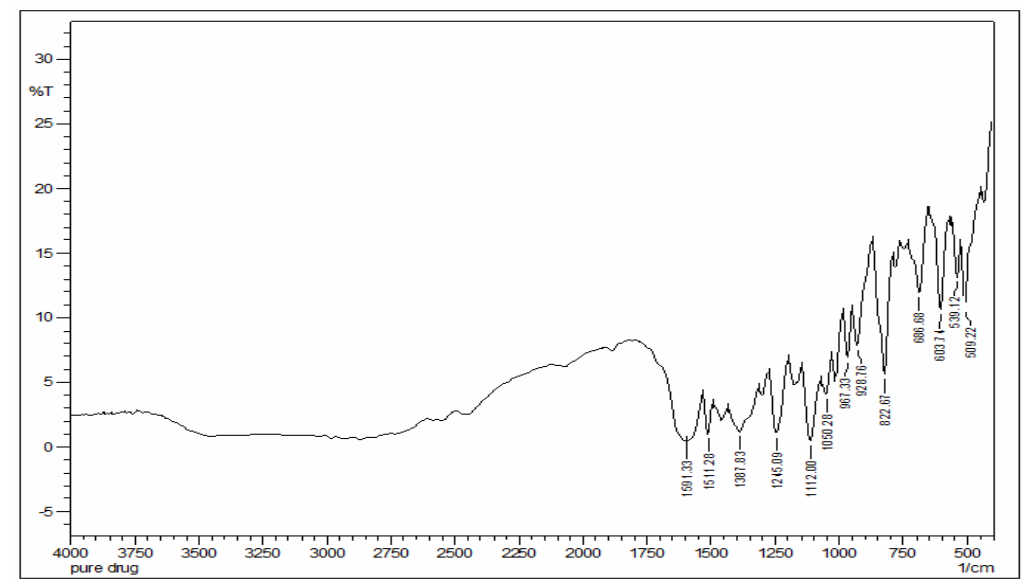

Figure 6. IR spectra of metoprolol tartrate

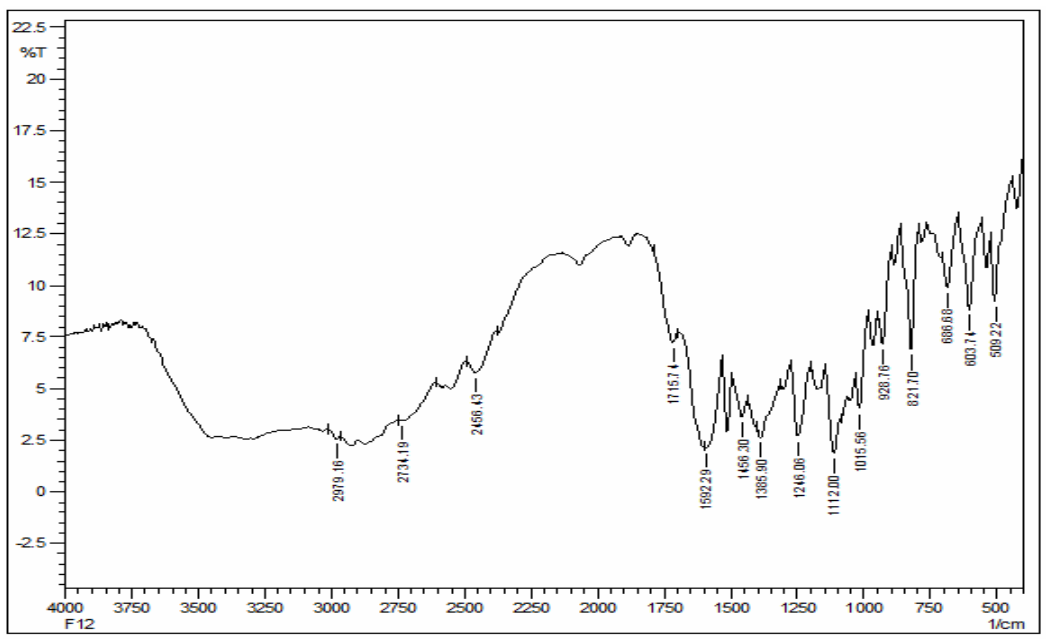

Figure 7. IR spectra of formulation $\mathrm{FH}_{4}$ (containing HPMC K4M)

Table 1. Composition of buccal tablets of metoprolol tartrate.

\begin{tabular}{llllllllllllllll}
\hline $\begin{array}{l}\text { Ingredients } \\
\text { mg/tablet }\end{array}$ & \multicolumn{10}{c}{ Formulation code } \\
\cline { 2 - 12 } & $\mathrm{FC}_{0}$ & $\mathrm{FC}_{1}$ & $\mathrm{FC}_{2}$ & $\mathrm{FC}_{3}$ & $\mathrm{FC}_{4}$ & $\mathrm{FA}_{0}$ & $\mathrm{FA}_{1}$ & $\mathrm{FA}_{2}$ & $\mathrm{FA}_{3}$ & $\mathrm{FA}_{4}$ & $\mathrm{FH}_{0}$ & $\mathrm{FH}_{1}$ & $\mathrm{FH}_{2}$ & $\mathrm{FH}_{3}$ & $\mathrm{FH}_{4}$ \\
\hline $\begin{array}{l}\text { Metoprolol } \\
\text { tartrate }\end{array}$ & 100 & 100 & 100 & 100 & 100 & 100 & 100 & 100 & 100 & 100 & 100 & 100 & 100 & 100 & 100 \\
$\begin{array}{l}\text { Carbopol } \\
934 \mathrm{p}\end{array}$ & - & 12 & 16 & 20 & 24 & - & 12 & 16 & 20 & 24 & - & 12 & 16 & 20 & 24 \\
$\begin{array}{l}\text { Sodium CMC } \\
\text { Sodium }\end{array}$ & 80 & 68 & 64 & 60 & 56 & - & - & - & - & - & - & - & - & - & - \\
alginate & - & - & - & - & - & 80 & 68 & 64 & 60 & 56 & - & - & - & - & - \\
HPMC K4M & - & - & - & - & - & - & - & - & - & - & 80 & 68 & 64 & 60 & 56 \\
Mannitol & 16 & 16 & 16 & 16 & 16 & 16 & 16 & 16 & 16 & 16 & 16 & 16 & 16 & 16 & 16 \\
SSF & 4 & 4 & 4 & 4 & 4 & 4 & 4 & 4 & 4 & 4 & 4 & 4 & 4 & 4 & 4 \\
$\begin{array}{l}\text { Ethyl } \\
\text { cellulose }\end{array}$ & 50 & 50 & 50 & 50 & 50 & 50 & 50 & 50 & 50 & 50 & 50 & 50 & 50 & 50 & 50 \\
Total & 250 & 250 & 250 & 250 & 250 & 250 & 250 & 250 & 250 & 250 & 250 & 250 & 250 & 250 & 250 \\
\hline
\end{tabular}

$\mathrm{FC}=$ formulation containing sodium $\mathrm{CMC} ; \mathrm{FA}=$ Formulation containing sodium alginate; $\mathrm{FH}=$ Formulation containing containing HPMC $\mathrm{K} 4 \mathrm{~K}$

The in vitro release parameter values $\left(\mathrm{t}_{25 \%}\right.$, $\mathrm{t}_{50 \%}$ and $\mathrm{t}_{70 \%}$ ) displayed by the various formulations range from 0.27 to $1.03 \mathrm{hr}\left(\mathrm{t}_{25 \%}\right), 1.48$ to $5.27 \mathrm{hr}$ $\left(\mathrm{t}_{50 \%}\right), 4.09$ to $8 \mathrm{hr}\left(\mathrm{t}_{70 \%}\right)$ respectively. The 
formulation $\mathrm{FA}_{1}$ containing sodium alginate $(34.00 \%$ $\mathrm{w} / \mathrm{w}$ of matrix layer), carbopol $934 \mathrm{p}(6.0 \% \mathrm{w} / \mathrm{w}$ of matrix layer) and mannitol (channeling agent, 8.0\% $\mathrm{w} / \mathrm{w}$ of matrix layer) was found to be promising, which showed $t_{25 \%}, t_{50 \%}$ and $t_{70 \%}$ values of $0.42,2.45$, $4.48 \mathrm{hr}$ respectively and in vitro drug release of $86.04 \%$ in $8 \mathrm{hr}$ along with satisfactory bioadhesive strength $(5.00 \pm 0.10 \mathrm{~g})$.

Drug-excipient interactions were studied by IR spectroscopy analysis of the samples $\left(\mathrm{FC}_{4}, \mathrm{FA}_{4}, \mathrm{FH}_{4}\right)$ stored for three months at $40 \pm 2^{\circ} \mathrm{C}$ and $75 \pm 5 \% \mathrm{RH}$. The IR spectrum of the pure drug metoprolol tartrate displayed characteristic peaks at $3648.00 \mathrm{~cm}^{-1}$, $1591.33 \mathrm{~cm}^{-1}$ and $1245.09 \mathrm{~cm}^{-1}$ due to $\mathrm{O}-\mathrm{H}, \mathrm{C}=\mathrm{O}$ and C-N groups, respectively. The peaks of $2880.00 \mathrm{~cm}^{-1}$ and $1112.00 \mathrm{~cm}^{-1}$ are due to $\mathrm{C}-\mathrm{H}$ group and alkyl aryl ether linkage, respectively. All the above characteristic peaks of the pure drug were also found in the IR spectrum of the formulation $\mathrm{FC}_{4}$ (peaks at $3650.00 \mathrm{~cm}^{-1}, 1589.10 \mathrm{~cm}^{-1}$ and $1246.06 \mathrm{~cm}^{-1}$ due to $\mathrm{O}-\mathrm{H}, \mathrm{C}=\mathrm{O} \& \mathrm{C}-\mathrm{N}$ groups, respectively), $\mathrm{FA}_{4}$ (peaks at $3650.00 \mathrm{~cm}^{-1}, 1590.36 \mathrm{~cm}^{-1}$ and $1246.06 \mathrm{~cm}^{-1}$ due to $\mathrm{O}-\mathrm{H}, \mathrm{C}=\mathrm{O}$ and $\mathrm{C}-\mathrm{N}$, groups respectively), $\mathrm{FH}_{4}$ (peaks at $3700.00 \mathrm{~cm}^{-1}, 1592.29 \mathrm{~cm}^{-1}$ and 1246.06 $\mathrm{cm}^{-1}$ due to $\mathrm{O}-\mathrm{H}, \mathrm{C}=\mathrm{O}$ and $\mathrm{C}-\mathrm{N}$ groups respectively). The presence of above peaks indicates undisturbed structure of drug in the above formulation. Hence, there are no drug-excipient interactions. IR spectra of metoprolol tartrate (pure drug) and $\mathrm{FH}_{4}$ are shown in fig-6 and 7.

From the stability studies data it can be seen that the drug content of the formulation $\mathrm{FA}_{1}$ was not significantly affected at $40 \pm 2^{\circ} \mathrm{C} / 75 \pm 5 \% \mathrm{RH}$ after storage for three months. Statistical analysis of the drug content data (' $\mathrm{t}$ ' test) gives $\mathrm{t}$ values ranging from 0.62 to 1.30 which are much less compared to the table value of $4.3(\mathrm{p}<0.05)$.

\section{CONCLUSION}

The present study conclusively indicates that, among the fifteen formulations, the formulation $\mathrm{FA}_{1}$ containing sodium alginate $(34.00 \% \mathrm{w} / \mathrm{w}$ of matrix layer), carbopol $934 \mathrm{p}(6.0 \% \mathrm{w} / \mathrm{w}$ of matrix layer) and mannitol (channeling agent, $8.0 \% \mathrm{w} / \mathrm{w}$ of matrix layer) was found to be promising, which showed $t_{25 \%}$, $\mathrm{t}_{50 \%}$ and $\mathrm{t}_{70 \%}$ values of $0.42,2.45$ and $4.48 \mathrm{hr}$ respectively and in vitro drug release of $86.04 \%$ in 8 $\mathrm{hr}$ along with satisfactory bioadhesive strength $(5.00 \pm 0.10 \mathrm{~g})$.

\section{ACKNOWLEDGEMENTS}

The authors are thankful to Astra Zeneca Ltd., Bengaluru for providing gift sample of Metoprolol Tartrate and BLDEA's College of Pharmacy, Bijapur for their help in getting the IR done.

\section{REFERENCES}

1. Shojaei, A.H., Chang, R.K., Guo, X., Burnside, B.A. 2001. Systemic drug delivery via the buccal mucosal route. Pharm. Tech. 70-81.

2. Harries, D., Robinson, J.R. 1992. Drug delivery via the mucous membranes of the oral cavity. J. Pharm. Sci. 81, $1-10$.

3. Beckett, A.H., Hossie, R.D. 1971. Buccal absorption of drugs. Handbuch der Experimentellenpharmakologie; Gillette. Berline. 28, 1-60.

4. Vyas, S.P., Khar, K.R. 2002. Controlled drug delivery concepts and advances. 1st ed. Vallabh prakashan, New Delhi, p. 292.

5. [updated 2010 May 6; cited 2010 May 11]. Available from: http://en.wikipedia.org/wiki/metoprolol.

6. Perioli, L., Ambrogiv, V., Stefano, G., Ricci, M., Blasi, P., Carlo, R. 2007. Mucoadhesive bilayered tablets for buccal sustained release of flubiprofen. AAPS. Pharm. Sci. Tech. 8, E1-E6.

7. Derle, D., Joshi, O., Pawar, A., Patel, J., Amol, J. 2009. Formulation and evaluation of buccoadhesive bi-layer tablet of propranolol hydrochloride. Int. J. Pharm. Pharm. Tech. 1, 206-212.

8. Desai, K.G.H., Kumar, T.M.P. 2004. Preparation and evaluation of a novel buccal adhesive systems. AAPS. Pharm. Sci. Tech. 5, 1-9.

9. Madgulkar, A., Bhalekar, M., Wable, N., Patel, K., Kolhe, V. 2008. Egg shell membrane as substrate for bioadhesion measures. Indian. Drugs. 45, 219-21.

10. Prasad, B.K., Remeth, J.D., Kailas, K.M., Vijay, D.H., Niranjan, S.M. 2008. Formulation and evaluation of buccoadhesive tablet of atenolol. J. Pharm. Res. 1(2), 193-9.

11. Swamy, P.V., Singh, P., Hiremath, S.N., Shirsand, S.B., Neelima, Raju, S.A. 2007. Preparation and evaluation of chitosan buccal film of diltiazem hydrochloride. Indian. Drugs. 44, 137-139. 